UNIVERSIDADE FEDERAL DO RIO GRANDE DO SUL PROGRAMA DE PÓS-GRADUAÇÃO DE INFORMÁTICA NA EDUCAÇ̃̃O -PPGIE

\title{
METODOLOGIA DOS DESAFIOS e a Epistemologia Construtivista
}

\section{Clovis Leopoldo Reichert}

Fevereiro 2004 


\section{SUMÁRIO}

1. Introdução

2. A metodologia dos Desafios

2.1. Peculiaridades e significado pedagógico

2.2. A epistemologia construtivista e a Metodologia dos Desafios

3. A função da ação e da experiência na Metodologia dos Desafios

4. Metodologia dos Desafios e aprendizagem 


\section{1- Introdução}

A compreensão dos aspectos que permeiam o processo de construção do conhecimento e da aprendizagem humana caracteriza, em si mesma, um grande desafio para educandos e educadores. Em sintonia com o cenário mundial que se apresenta cada vez mais exigente e desafiador aos profissionais da área tecnológica, o SENAI ${ }^{1}$ procura desempenhar sua missão e sua vocação para a formação de técnicos cada vez melhor habilitados e qualificados para o mundo do trabalho industrial.

$\mathrm{Na}$ busca de soluções que atendam às novas demandas educacionais, o SENAI tem incorporado novas tecnologias de informação e comunicação aos processos de ensinoaprendizagem presenciais tradicionais. Projetos estratégicos, com o objetivo de democratizar a educação profissional, propiciam oportunidades de construção do conhecimento, independentemente de local ou espaço físico. Através da criação de um modelo de ensino a distância e com o uso de materiais didáticos impressos e em ambiente web, estão sendo implementadas ações educacionais fundamentadas em concepções epistemológicas construtivistas.

O objetivo do presente trabalho é apresentar a estrutura da Metodologia dos Desafios com relação às fundamentações da epistemologia genética construtivista de Jean Piaget.

${ }^{1}$ SENAI - Serviço Nacional de Aprendizagem Industrial - instituição mantida e administrada pela indústria. 


\section{2- A Metodologia dos Desafios}

Contribuir para a construção desta metodologia e viver esta experiência com total participação e dedicação ao processo, tem sido acontecimentos de enriquecimento pessoal e profissional.

A Metodologia dos Desafios, criada em 2000 e 2001 por uma equipe multidisciplinar do SENAI, de forma colaborativa, foi pensada para ser usada em ambientes virtuais de aprendizagem. Seu foco principal gira em torno da resolução de problemas ${ }^{2}$.

Não se trata simplesmente das alternativas metodológicas geradas pelo movimento da Escola Nova, cujo precursor foi John Dewey, que muito influenciou a educação no país a partir do início do século XX. Esta metodologia, indo além, procura apropriar-se de algumas de suas características para aplicá-las a programas de educação a distância.

\section{1- Peculiaridades e significado pedagógico}

A Metodologia dos Desafios está alicerçada em um ambiente virtual que favorece a interação entre os atores do processo educacional (alunos, facilitadores, professores). Não existe a concepção de aula, no sentido clássico de exposição de conteúdos previamente selecionados pelo professor para cada evento educacional.

Assim, os alunos, em grupo, trabalham na resolução de desafios que foram definidos pelas equipes de elaboração do curso. O conjunto de desafios propostos é definido em função do perfil profissional de saída pretendido, bem como das competências requeridas pelo mercado profissional. Conforme definido pela Metodologia, para cursos online é recomendado um número reduzido de Desafios, geralmente entre 4 e 5, com nível de complexidade crescente.

\footnotetext{
${ }^{2}$ A Metodologia dos Desafios foi criada a partir do PBL (Problem Based Learning) e na Metodologia da Problematização

4 V. 2 № 1, Março, 2004
} 
Os primeiros desafios de qualquer curso que usam esta metodologia são resolvidos em grupo. Apresentam uma descrição da situação, definem o problema, os pontos a estudar sobre o problema, os textos, as atividades, os recursos de pesquisa, diversas fontes, recursos de comunicação com o professor, com o facilitador do ambiente web, além de atividades de avaliação e auto-avaliação. Os desafios compreendem também certos conteúdos e atividades que aparecem como casos de estudo, de modo a estimular níveis de pensamento diferenciados pelos alunos.

Já no Desafio Final, o aluno, situado na realidade do tema em foco, tem a oportunidade de exercitar de modo mais individualizado as habilidades de estudar e agir com iniciativa, autonomia, consciência política e responsabilidade ética, além da prática transformadora, decorrente de todo o processo de aprendizado pelo qual o aluno passou nos desafios anteriores.

Percebe-se que nesta metodologia também o princípio de aprender a pensar está aí impregnado. A interação constante entre alunos, organizados em grupos, possibilita a manutenção do princípio de ensino individualizado, porém não individualizante. $\mathrm{O}$ aluno não se isola. Pelo contrário, mantém-se em constante interação social e intelectual com os demais participantes do curso. A metodologia adotada, de trabalhos em grupo, mostra a importância da interação para a construção colaborativa de conhecimentos.

\section{2- A epistemologia construtivista e a Metodologia dos Desafios}

A Metodologia dos Desafios está alicerçada em uma visão prática, centrada na realidade. Em uma análise mais superficial seria possível ter-se a falsa impressão de que esta poderia ser entendida como uma metodologia educacional de fundo empirista.

Entretanto, não é possível caracterizar a Metodologia dos Desafios sob o conceito primordial empirista de que o conhecimento resulta da experiência e também não se pode classificá-la sob a visão behaviorista (expressão maior do empirismo), pois não são privilegiadas as condições exógenas do indivíduo. Ao contrário do behaviorismo, a Metodologia dos Desafios privilegia a capacidade de simbolização humana. Também o inatismo, que privilegia as condições endógenas e entende o indivíduo como sujeito 
detentor de todas as condições cognitivas com as quais estaria apto a enfrentar as circunstâncias de sua vida, não está configurado nesta metodologia.

A Epistemologia Genética, ao situar na ação do sujeito o núcleo a partir do qual se originam as sucessivas estruturas cognitivas, é a nossa âncora fundamental. A atividade do sujeito (ação) é o fator primordial na gênese do conhecimento.

A inteligência, de herança genética, inicia na fase fetal, mas é estruturada a partir do nascimento do indivíduo, quando o sujeito começa a interagir com o meio. A capacidade de aprender, independentemente da bagagem hereditária do indivíduo, é própria da espécie humana. Esta visão construtivista explica a constituição da inteligência como atividade organizadora, que prolonga e supera a organização biológica, elaborando novas estruturas.

A aprendizagem humana também pode ser definida a partir do conceito da construção de estruturas de assimilação. Estas estruturas, acolhendo o estímulo, ao mesmo tempo produzem respostas no processo de assimilação, relação fundamental envolvida em todo o desenvolvimento e em toda a aprendizagem humana.

A descrição da Metodologia dos Desafios, aqui apresentada, pode ser caracterizada pelos princípios fundamentais do construtivismo de Piaget, que advoga que o conhecimento é construído na interação entre sujeito e objeto, podendo o sujeito ser seu próprio objeto. 


\section{3- A função da ação e da experiência na Metodologia dos Desafios}

A Metodologia dos Desafios tem como uma de suas premissas desencadear as potencialidades e o desenvolvimento de seus alunos. Para tanto é privilegiada a ação do sujeito, pois o aluno aprende por conta das ações que ele mesmo pratica, interagindo com seu grupo e com o docente.

A relação entre prática e teoria, que deve levar em conta a realidade na qual está inserido o aluno, tem por objetivo transformá-lo, capacitando-o para atuar também como profissional responsável e transformador de seu meio (empresarial, social e ambiental), visando proporcionar melhor qualidade de vida para todos os envolvidos nos processos educacionais e nas atividades profissionais.

Considerando que esta metodologia é aplicada na educação a distância em ambientes virtuais, foi desenvolvida com o objetivo de proporcionar situações mobilizadoras do envolvimento e participação dos alunos para o estudo e para a aprendizagem significativa, superando características observadas em cursos tradicionais e mesmo em cursos a distância que reproduzem o modelo presencial.

Para tanto, os desafios propostos devem ser instigadores de uma situação real, que pode se configurar como problemática ou emblemática, requerendo uma proposta de soluções factíveis, calcadas na realidade do meio no qual o aluno está inserido.

As situações-problema apresentadas podem ser superadas pelos educandos na medida em que desenvolvem sua ação, através da análise, síntese e avaliação, com base nas estruturas pré-existentes. Neste contexto, cada aluno individualmente, e cada grupo coletivamente, podem determinar trajetórias de aprendizagem diferentes, decorrentes de suas condições e história pessoal e das estruturas pré-existentes. 


\section{4- Metodologia dos Desafios e aprendizagem}

Os desafios (ou situações-problema) são de fato recursos facilitadores dos processos de aprendizagem e da construção do conhecimento. Segundo Piaget, um estímulo somente se torna significativo na medida em que há uma estrutura que permite sua assimilação, uma estrutura que acolhe o estímulo e, ao mesmo tempo, produz respostas à sua apresentação.

Piaget atribui quatro fatores primordiais ao desenvolvimento cognitivo: o desenvolvimento do sistema nervoso (maturação), a experiência do indivíduo (física e lógico-matemática), a transmissão social (interação) e a equilibração (ou autoregulação). Todos estes fatores são necessários, mas não suficientes quando analisados isoladamente. A equilibração é que possibilita a síntese e proporciona a unidade ao processo de desenvolvimento; neste contexto, o desenvolvimento é caracterizado por conflitos e incompatibilidades momentâneas que precisam ser suplantados, para que se alcance um nível mais elevado de equilíbrio

Segundo Piaget, a aprendizagem humana não se dá isoladamente por força da bagagem hereditária, nem pelo meio, mas sim pela interação ativa do sujeito da aprendizagem. Esta interação ativa, ação do sujeito, compreende sempre duas dimensões: a de assimilação (transformação do objeto) e a de acomodação (transformação do sujeito). A formação de um novo hábito (acomodação) é decorrência de uma diferenciação de esquemas anteriores.

Em geral, a aprendizagem é provocada por situações - provocada por um experimentador psicológico; ou por um professor, com referência a algum ponto didático; ou por uma situação externa. Ela é provocada, em geral, como oposta ao que é espontâneo. Além disso, é um processo limitado a um problema simples ou uma estrutura simples (Piaget, 1972). 
À medida que o sujeito exercita os seus esquemas existentes ele os modifica, aprendendo mais quando as situações e objetos são diferentes dos anteriores. Os desafios propostos nesta Metodologia são apresentados em crescimento de complexidade, requerendo dos alunos as habilidades elaboração de novos esquemas para a construção dos conhecimentos.

\section{1 - Aprender a aprender}

A estrutura de Atividades e Pontos-chave que compõem os Desafios são ferramentas que possibilitam o aprender a aprender. Não existe transmissão de conteúdos a partir de uma estrutura de conteúdos pré-definida, conforme tradicionalmente entendida, apenas orientações destinadas a manter o foco e o escopo das competências previstas e legalmente homologadas para os respectivos cursos.

A Metodologia dos Desafios apresenta um sentido pedagógico dos mais elevados: o de apresentar intencional e sistematicamente desafios de diferentes formas e em diferentes níveis, para propiciar a construção do conhecimento de forma autônoma e também colaborativa, para a formação de profissionais que se preparam para atuarem de forma eficiente em seu meio profissional.

Neste processo de aprender a aprender é importante a compreensão de que o conteúdo é meio, e não objetivo da aprendizagem. Os alunos são incentivados a buscar resultados de aprendizagem através da pesquisa e adequação de novas informações, da leitura e do estudo organizado. Estes estudos podem ser individuais e/ou no grupo ao qual o aluno está integrado. 


\section{5- O papel do professor no ambiente virtual da Metodologia dos Desafios}

Um dos importantes aspectos considerados na elaboração da Metodologia dos Desafios foi o papel do professor no ambiente virtual do curso.

A discussão deste tema iniciou no enfoque da denominação mais adequada: professor, docente, tutor, facilitador, mediador, entre tantas outras. A denominação escolhida foi docente, porém ficando claro o entendimento de que mediação, orientação, motivação, etc, são características essenciais do perfil do docente de Educação a Distância.

Alicia Fernandes nos lembra que para que o professor seja realmente um mediador, principalmente dentro de ambientes virtuais, é importante que o assistencialismo seja substituído por uma real preocupação com a formação do aluno-cidadão. A formação do aluno-cidadão implica em torná-lo autor e personagem ativo de seu destino, buscando estabelecer um diferencial significativo e romper com a relação tradicional da dependência de um professor que "ensina".

Esta independência nos leva a uma nova visão, uma visão de construção colaborativa do conhecimento, onde a aprendizagem não se dá mais sob a condução estreita do professor, mas passa a acontecer em um cenário amplo de valorização das estruturas e conhecimentos prévios dos aprendentes, de proposição de idéias, inclusão de conceitos e visões. 


\section{6- Conclusão}

As exigências de que sejamos, cada um de nós, sujeito capaz, crítico e criativo nesta nova sociedade do conhecimento passam a ser uma das barreiras ao ingresso de muitos no mundo educacional virtual. O "Analfabetismo Tecnológico" ainda é fator terrível de exclusão.

Outro aspecto que funciona como um "freio" que inibe a transformação de ambientes educacionais em ambientes de aprendizagem é o próprio sistema de promoção escolar. O "passar de ano" está ainda profundamente acorrentado a um sistema de avaliação arcaico, pois considera somente momentos de avaliação, sistema este preocupado em validar conhecimentos de um currículo pré-formatado.

Esta sistemática, a meu ver, é muito inadequada frente a esta proposta de sociedade da informação na qual o desenvolvimento das tecnologias pode criar um ambiente cultural e educativo suscetível de diversificar as fontes do conhecimento e do saber, caracterizadas por uma complexidade crescente e pela gama cada vez mais ampla de possibilidades que oferecem.

A Metodologia dos Desafios é um esforço consciente do SENAI de acompanhar plenamente este avanço científico-tecnológico e de oferecer condições para um processo de aprendizagem efetivamente centrado na relação professor-aluno.

Porém, inúmeros programas educacionais, despreocupados destes fatores fundamentais da construção do conhecimento em bases epistemológicas de qualidade, não possibilitam à maioria dos estudantes e professores o acesso aos melhores recursos pedagógicos, e com isso, inibem o real despertar da tão desejada e esperada "sociedade do conhecimento". 


\section{BIBLIOGRAFIA}

BECKER, Fernando. A Origem do conhecimento e a Aprendizagem Escolar. Porto Alegre, ARTMED Editora.

BECKER, Fernando. Educação e Construção do Conhecimento. Porto Alegre, ARTMED Editora.

BECKER, Fernando. Da Ação à Operação. O Caminho da Aprendizagem. Porto Alegre, EST. Palmarinca.: Educação e Realidade, 1993, 160 p.

FERNANDEZ, Alicia. O saber em jogo. A psicopedagogia propiciando autorias de pensamento. Porto Alegre, ARTMED Editora, 2001 (cap. 5 e 6)

KESSERLING, Thomas. Os quatro níveis de conhecimento em Jean Piaget. Porto Alegre. Educação e Realidade, 15(1): 3-22, Jan/Jun 1990.

MONTOYA, A. Piaget e a criança favelada - Epistemologia genética, diagnóstico e soluções. Petrópolis, Vozes, 1996.

Piaget, Jean. Aprendizagem e Conhecimento. Cópia de capítulo.

PIAGET, Jean. Development and learning. in LAVATELLY, C. S. e STENDLER, F. Reading in child behavior and development. New York: Hartcourt Brace Janovich, 1972

Piaget, Jean. O Desenvolvimento do Pensamento. Lisboa, Publicaç eos Dom Quixote, $1977,228 \mathrm{p}$.

Piaget, Jean. O Nascimento da Inteligência na Criança. Rio de Janeiro, Zahar Editores, $1978,389 \mathrm{p}$.

Piaget, Jean. Problemas de Psicologia Genética. Série os Pensadores. Rio de Janeiro, Victor Civita, 1978

Piaget, Jean. Psicologia da Inteligência - Cap. Os Fatores do Desenvolvimento Intelectual. p. 201-06.

SENAI. DN. A metodologia dos Desafios. Brasília, 200272 p. (Série Documentos Metodológicos, 1) 